\title{
Simultaneous Production of Xylitol and Ethanol from Different Hemicellulose Waste Substrates by Candida tropicalis Strain Ly15
}

Kaliyan Barathikannan, Ameer Khusro and Agastian Paul*

Research Department of Plant Biology and Biotechnology, School of Life Science, Loyola College, Nungambakkam, Chennai, Tamil Nadu, India

\begin{abstract}
In the present study, we optimized the parameters for maximum yield of xylitol and ethanol by Candida tropicalis strain LY15 utilizing different Hemicellulosic Waste substrates (HWs) obtained by Acid-Alkaline hydrolysis method. Using the pomegranate peel as substrate, higher yield of xylose reductase, xylitol and ethanol were obtained. The optimal level of variables such as inoculum, HWs concentration, time period and RPM (agitation speed) were determined by the response surface methodology, with a significant co-efficient determination of $R^{2}=0.89$. Positive correlation was obtained with our experimental and predicted values. The interactions with the ideal levels of inoculum (1\%), HWs (Pomegranate peel) (2\%), time period $(60 \mathrm{~h})$ and RPM (140) showed highly significance values of xylose reductase $(171.5 \mathrm{IU} / \mathrm{mL})$, xylitol $\left(55.57 \mathrm{~g} \mathrm{l}^{-1}\right)$ and ethanol $\left(3.37 \mathrm{~g} \mathrm{l}^{-1}\right)$ at an incubation period of $60 \mathrm{~h}$. The dual yield produced by Candida tropicalis strain LY15 using pomegranate peel makes the organism potent candidate for industrial application.
\end{abstract}

Keywords: Hemicellulosic waste substrate (HWs); Candida tropicalis; Pomegranate peel; Xylose reductase; Xylitol; Ethanol

\section{Introduction}

Hemicellulosic resources such as agricultural residues, forestry, municipal wastes and other cost-effective biomasses are the plentiful and renewable source of sugar substrate [1]. Alternatively, bioconversion method has been employed in recent years owing to its cost effectiveness. A good choice of hemicellulosic source and microorganism that can utilize xylose is vital in the biological pathway $[2,3]$. A different type of lignocellosic biomass gives the different type of composition in cellulose, hemicellulose, and lignin [4].

Xylitol is a five-carbon sugar which are major constituents of food and medicine technologies. The natural essential sources of xylitol are vegetables and fruits such as strawberries, yellow plum, lettuce, raspberries and cauliflower. Xylitol is used for low caloric sweetener as an appropriate sugar substitute for diabetic patients [5]. In last few years, several commercial applications of xylitol have been achieved in industries like food, dental and pharmaceuticals [6]. Increasing interest in xylitol has led to a huge demand for the product globally. Bioconversion of xylose to xylitol can be carried out by microorganisms such as bacteria, fungi and yeast. Xylitol production is influenced by various factors in a culture medium. In recent times, significant attention has been drawn to the production of xylitol from xylose [7]. High substrate concentration is imperative for the production of xylitol in a cost-effective way for scale up process. Significant steps towards the strain improvement for xylitol-production have been assumed [8-10].

The current xylitol production methodology involves chemical procedures by the hydrogenation of D-xylose in the presence of nickel catalyst at selective parameters [11]. However, the major drawback in chemical process is the high cost of refinement methods. Recently, biotechnological processes were explored for xylitol production to remove the limitations at the different stages of the chemical processes. This substitute production corresponds to the bioconversion of $\mathrm{D}$-xylose to xylitol by microorganisms. At a moderate costs and renewable biomass from agro-industrial waste, it can be used a source of D-xylose. Microorganisms can also be metabolically engineered in order to convert the reducing sugars in hemicellulosic hydrolysates to xylitol. Recently, studies on the bio conversion of xylose into xylitol are the current area of interest [12-15]. Successful production and optimization of xylitol had been achieved by various yeast isolates $[3,16]$.

In last decade, the biomass based ethanol production has also enlarged in this area; but the bioethanol production is costly. The cost of the traditionally used raw materials constitutes about $40 \%-70 \%$ of the total production cost [17]. The only alternative is to use fewer cheap materials, such as agricultural waste that can make the process cost-effective considerably $[18,19]$. In recent years a significant attempt had also been taken into account for the co-production of xylitol and ethanol using cheap substrates [20].

Hence, retaining in view of the tremendous value of xylitol and ethanol production, challenge has been made to explain xylitol enzymatic production (Xylose reductase) from C. tropicalis using different hemicellulosic waste through Box-Behnken design (BBD) that would contribute towards the simultaneous production of xylitol and ethanol in a cost-effective manner.

\section{Materials and Methods}

\section{Raw material of hemicellulosic waste substrates (HWs)}

The different hemicellulosic waste (HW) and flours used in this study were Paddy straw, Sugarcane bagasses, Corn cob, Pomegranate peel, Sweet Lime (Mosambiae) peels, Banana peel, Rice flour, Wheat flour, Ragi flour, Coconut oil cake, Groundnut oil cake, Sesame Oil

*Corresponding author: Agastian Paul, Research Department of Plant Biology and Biotechnology, School of Life Science, Loyola College, Nungambakkam, Chennai-34, Tamil Nadu, India, Tel: +919444433117; Fax: +4428175566; E-mail: agastianloyolacollege@gmail.com

Received October 31, 2016; Accepted November 28, 2016; Published November 30, 2016

Citation: Barathikannan K, Khusro A, Paul A (2016) Simultaneous Production of Xylitol and Ethanol from Different Hemicellulose Waste Substrates by Candida tropicalis Strain Ly15. J Bioprocess Biotech 6: 289. doi:10.4172/21559821.1000289

Copyright: (c) 2016 Barathikannan K, et al. This is an open-access article distributed under the terms of the Creative Commons Attribution License, which permits unrestricted use, distribution, and reproduction in any medium, provided the original author and source are credited. 
Cake. The corncob particles were sun dried for $48 \mathrm{~h}$ then stored at room temperature in plastic bags for further use. The collected HW substrates were ground and sieved ranging from $0.45 \mathrm{~mm}$ to $0.9 \mathrm{~mm}(20-40$ mesh) and used in future experiments. The cellulose, hemicellulose and lignin content were determined experimentally according to the methodology of Adeeyo et al. [21].

\section{Acid and alkaline pretreatment}

The acid and alkaline pretreatment were carried out in $250 \mathrm{ml}$ Erlenmeyer flask. Ten grams of HWs were soaked into $2 \% \mathrm{NaOH}$ at a solid-liquid ratio of $1: 3$ and mixed with dilute acid $(0.5 \%(\mathrm{w} / \mathrm{w})$ $\left.\mathrm{H}_{2} \mathrm{SO}_{4}+1.5 \%(\mathrm{w} / \mathrm{w}) \mathrm{H}_{3} \mathrm{PO}_{4}\right)$ and pretreated in an autoclave at $130^{\circ} \mathrm{C}$ with a residence time of $60 \mathrm{~min}$.

\section{Microorganism and fermentation experiments}

Candida tropicalis LY15 was screened and identified in previous studies. Candida tropicalis strain LY15 (KJ734199) was grown in the preculture medium containing $10 \mathrm{~g} \mathrm{l}^{-1}$ yeast extract, $20 \mathrm{~g} \mathrm{l}^{-1}$ peptone, and $20 \mathrm{~g} \mathrm{l}^{-1}$ dextrose. The seed cells were inoculated in $100 \mathrm{ml}$ preculture medium and incubated at $28^{\circ} \mathrm{C}$ and $140 \mathrm{rpm}$ for $14 \mathrm{~h}$ and again inoculated into the freshly prepared fermentation medium at $10 \%(\mathrm{v} / \mathrm{v})$.

\section{Shake flask fermentation conditions using hemicellosic waste substrates}

Fermentation was carried out in the pretreated HW substrates at $\mathrm{pH}$ 7. This was supplemented with different nutrient concentration for tests according to the selected factorial design. After sterilization and cooling at room temperature, the flasks were inoculated with $1 \mathrm{ml}$ of culture broth. The flasks were incubated at $28^{\circ} \mathrm{C}$ at $140 \mathrm{rpm}$ for $48 \mathrm{~h}$. During the preliminary screening, the experiments were performed for $90 \mathrm{~h}$ and it the maximum production was obtained in $60 \mathrm{~h}$.

\section{Preparation of cell-free extracts}

Every $12 \mathrm{~h}$ fermented product were centrifuged at $6,000 \mathrm{rpm}$ at $20^{\circ} \mathrm{C}$ for $10 \mathrm{~min}$ and washed with sterile distilled water. Cell disruption was performed in a homogenizer for $15 \mathrm{~min}$ and the slurry was centrifuged $\left(12,000 \mathrm{rpm}\right.$ at $4^{\circ} \mathrm{C}$ for $\left.20 \mathrm{~min}\right)$. The supernatant collected, was used for enzyme analysis.

\section{Xylose reductase activity}

Xylose reductase (XR) activity was determined spectrophotometrically using a UV-Visible (ELICO Double Beam SL-210) spectrophotometer at $340 \mathrm{~nm}$. The final reaction mixture contained (in $1 \mathrm{ml}$ ) $500 \mu \mathrm{l}$ of $250 \mathrm{mM}$ potassium phosphate buffer (pH 7.0), $100 \mu$ l of $100 \mathrm{mM}$ mercaptoethanol, $50 \mu \mathrm{l}$ of $0.5 \mathrm{M}$ D-Xylose, $200 \mu \mathrm{l}$ of distilled water, $50 \mu \mathrm{l}$ of $3.4 \mathrm{mM} \mathrm{NADPH}$. The elimination of endogenous oxidation of $\mathrm{NAD}(\mathrm{P}) \mathrm{H}$ was done by setting the reaction mixture for $1 \mathrm{~min}$. $200 \mu \mathrm{l}$ of enzyme solution was added to the reaction mixture in order to initiate the reaction. One unit of xylose reductase activity was defined as the amount of enzymes that can oxidize one micromole $\mathrm{NAD}(\mathrm{P}) \mathrm{H}$ per minute. The enzyme activity was calculated for the respective isolates.

\section{Ethanol estimation}

The effect of different HWs for ethanol production using yeast cells was performed. After the completion of fermentation, samples were analyzed for alcohol content using 'Sigma- Aldrich Ethanol Assay Kit'. The experiment was performed to estimate ethanol production by yeast cells for the presence of HW substrates.

\section{Analytical method}

Xylitol concentration were determined using the equipped with refractive index detector and Aminex HPX-87H column (Bio-Rad, Richmond, USA) with $0.01 \mathrm{~N} \mathrm{H}_{2} \mathrm{SO}_{4}$ as the mobile phase running at $0.6 \mathrm{~mL} / \mathrm{min}$ at $45^{\circ} \mathrm{C}$ as previously described [5]. The retention time of xylitol was $11.4 \mathrm{~min}$. These samples were centrifuged in order to separate suspended materials and filtered again through $0.2 \mu \mathrm{m}$ poresized syringe filters.

\section{Statistical optimization of selective parameters for xylose reductase production}

Box-Behnken design (BBD) was adopted to optimize selective independent parameter viz., inoculum, HWs, time period and RPM (agitation speed) to maximize xylose reductase production or response by keeping $\mathrm{pH}$, temperature constant. BBD is an optimization method for the small number of variables that estimates best-fit parameters of the quadratic models. It detects not only the lack of fit into the model but also constructs a sequential design for response surface methodology. According to the present experimental design, the total number of treatment combinations is $2 \mathrm{k}+2 \mathrm{k}+\mathrm{n}$, where ' $\mathrm{k}$ ' is the number of independent variables and ' $n$ ' is the number of repetition of experiments at the Central point.

The experimental design consisted of 29 runs of four variables (A, $\mathrm{B}, \mathrm{C}, \mathrm{D})$ at three levels $(-1,0,+1)$ in order to optimize the medium components. The concealed values -1 and +1 indicate as low and high level of the variables studied based on our previous experiments. All variables were set at a central coded value of zero.

The experimental plan of independent variables with respect to their values in actual and coded form is represented in Table 1. All the experiments were performed in triplicates, and average enzyme activity obtained was taken as the response $(\mathrm{Y})$. The coefficient of determination $\mathrm{R}^{2}$ represents the goodness of fit of the polynomial equation and significance level was validated by $\mathrm{F}$ test. The desirability was kept at maximum.

\section{Software used}

The independent variables of the experimental were optimized and interpreted using Design Expert Version 10.0 (Stat-Ease Inc., Minneapolis, Minnesota, USA) statistical software.

\section{Validation of the experimental design}

The statistical analysis was validated for enzyme production in shake flask conditions using optimized parameters. The experiments were carried out in triplicates, and the enzyme activity was estimated according to the protocol described earlier.

\section{Statistical analysis}

All the experiments were carried out in triplicate and data presented are Mean \pm SD

\section{Results}

\section{Composition and pretreatment of different HWs}

Several findings reported the role of agricultural wastes containing hemicellulose as a substrate in the production of xylitol from microorganisms by secreting xylose reductase. Table 2 clearly shows the compositional analysis of different HWs. Natural biomass is the good source of cellulose and hemicellulose for obtaining useful products. 
Citation: Barathikannan K, Khusro A, Paul A (2016) Simultaneous Production of Xylitol and Ethanol from Different Hemicellulose Waste Substrates by Candida tropicalis Strain Ly15. J Bioprocess Biotech 6: 289. doi:10.4172/2155-9821.1000289

Page 3 of 8

\begin{tabular}{|c|c|c|c|c|}
\hline \multirow{2}{*}{ Variables } & \multirow{2}{*}{ Code } & \multicolumn{4}{|c|}{ Range and levels } \\
\cline { 2 - 5 } & & $\mathbf{- 1}$ & $\mathbf{0}$ & $\mathbf{+ 1}$ \\
\hline Inoculum (\%) & A & 0.5 & $\mathbf{1 . 0}$ & 1.5 \\
\hline HWs (Carbon Source \%) & B & 1.0 & $\mathbf{2 . 0}$ & 3.0 \\
\hline Time Period (Hours) & C & 48 & $\mathbf{6 0}$ & 72 \\
\hline RPM & D & 120 & $\mathbf{1 4 0}$ & 160 \\
\hline
\end{tabular}

Table 1: Experimental range, level and code of independent variables for BBD design.

\begin{tabular}{|c|c|c|c|}
\hline $\begin{array}{c}\text { Hemicellulose waste } \\
\text { substrates (HWs) }\end{array}$ & Hemicellulose (\%) & Cellulose (\%) & Lignin (\%) \\
\hline $\begin{array}{c}\text { Agricultural Waste } \\
\text { substrates }\end{array}$ & & & \\
\hline Paddy straw & $28.5 \pm 0.45$ & $48.6 \pm 0.51$ & $12.1 \pm 0.65$ \\
\hline Sugarcane bagasse & $27.1 \pm 0.46$ & $35.7 \pm 0.47$ & $9.4 \pm 0.50$ \\
\hline Corn cob & $31.5 \pm 0.62$ & $45.4 \pm 0.47$ & $16.1 \pm 0.45$ \\
\hline Flours & & & \\
\hline Rice & $25.5 \pm 0.48$ & $36.1 \pm 0.47$ & $18.6 \pm 0.81$ \\
\hline Wheat & $28.4 \pm 0.57$ & $28.4 \pm 0.65$ & $21.1 \pm 0.48$ \\
\hline Finger millet & $27 \pm 0.54$ & $39 \pm 0.51$ & $16 \pm 0.50$ \\
\hline Fruit Peels & & & \\
\hline Pomegranate Peel & $32.8 \pm 0.64$ & $27.6 \pm 0.68$ & $28.2 \pm 0.65$ \\
\hline Sweet Lime Peel & $26.2 \pm 0.39$ & $18.3 \pm 0.48$ & $8.9 \pm 0.47$ \\
\hline Banana Peel & $33.7 \pm 0.57$ & $30.3 \pm 0.87$ & $15.2 \pm 0.47$ \\
\hline Oil cakes & & & \\
\hline Groundnut & $18.5 \pm 0.29$ & $22.4 \pm 0.37$ & $7.1 \pm 0.41$ \\
\hline Sesame & $15.4 \pm 0.37$ & $21.8 \pm 0.31$ & $7.9 \pm 0.27$ \\
\hline Coconut & $17.8 \pm 0.47$ & $18.2 \pm 0.40$ & $5.5 \pm 0.40$ \\
\hline
\end{tabular}

Each value represents the mean \pm SD of triplicate experiments.

Table 2: Chemical Composition of different Hemicellulose waste substrates 2.

The acid and alkali hydrolysis $(2 \% \mathrm{v} / \mathrm{v})$ was very effective in releasing a sufficient amount of hemicellulose from different HWs (Table 2).

\section{Effect of different parameters in fermentation condition for the production of xylitol}

The xylose concentration is very important for the biomass and the production of xylitol. According to our experiment, increase in substrate (HWs) concentration upturns the xylitol productivity. The growth in xylitol production may be due to the increase in xylose reductase (XR) activity. Initial HWs concentration was $20 \mathrm{~g} / \mathrm{L}$ in order to estimate the effect of xylose concentration on xylitol yield.

\section{Effect of Inoculum}

The effect of inoculum level has a considerable impact on increasing the production of xylitol and ethanol. Maximum production of xylitol and ethanol was observed using Candida tropicalis strain LY15 at $1 \%$ inoculum level (Figure not shown).

\section{Effect of pretreatment hemicellosic waste substrate on xylitol production}

Pre-treatment not only liberates fermentable monomers but also weakens hydrogen bonding in-between glucan chains, which enhances the rate of polysaccharide breakdown into fermentable sugars in the presence of enzymes. The optimized and detoxified hydrolysate medium was supplemented with yeast extract 1.0, Peptone $2.0 \mathrm{KH}_{2} \mathrm{PO}_{4} 2.0$, $\mathrm{MgSO}_{4} \cdot 7 \mathrm{H}_{2} \mathrm{O} 0.3$ as a xylitol fermentation medium for the parent strain of Candida tropicalis strain LY15. The result revealed that $55.57 \mathrm{~g} \mathrm{l}^{-1}$ of xylitol was estimated in $60 \mathrm{~h}$ from $20 \mathrm{~g} / \mathrm{L}$ of HWs (pomegranate peel) with an ethanol yield of $3.37 \mathrm{gl}^{-1}$ under optimized parameters (Table 3).

\section{Effect of incubation period}

Incubation period plays a substantial role in the product formation. The isolate showed maximum xylitol and ethanol yield observed after $60 \mathrm{~h}$ of incubation. Lower and higher incubation period exposed decreased yield of xylitol and ethanol (Figure 1).

\section{Effect of agitation}

Agitation at $140 \mathrm{rpm}$ resulted in higher xylitol production and consequential ethanol concentration. The rate and efficiency of ethanol production were also significant with agitation up to $140 \mathrm{rpm}$ (Figure 2).

\section{Different HWs for bioproduction of xylitol and ethanol}

To examine if the solids (glucan and lignin) containing hydrolysate can be used directly in xylitol, and ethanol combined production, aerobic inhibitor degradation and xylitol fermentation were carried out using a HWs at a solids loading of $10 \%$. After the xylose was consumed totally, a shift to anaerobic simultaneous scarification and ethanol fermentation was performed with cellulase addition (15 filter paper units (FPU)/g substrate). However, the rate of inhibitor degradation and xylitol production is decreased, probably due to insufficient mass transfer. Furfural and 5-HMF were degraded totally after $36 \mathrm{~h}$ aerobic incubation. An increased xylitol concentration of $55.57 \mathrm{~g} \mathrm{l}^{-1}$ was obtained with a productivity of $20 \mathrm{~g}^{-1} \mathrm{HWs}$ (Pomegranate peel). Then, under anaerobic conditions by the addition $3.37 \mathrm{~g} \mathrm{l}^{-1}$ ethanol was produced after $60 \mathrm{~h}$ anaerobic fermentation, corresponding to $79.6 \%$ of the theoretical yield (Tables 3 and 4 ).

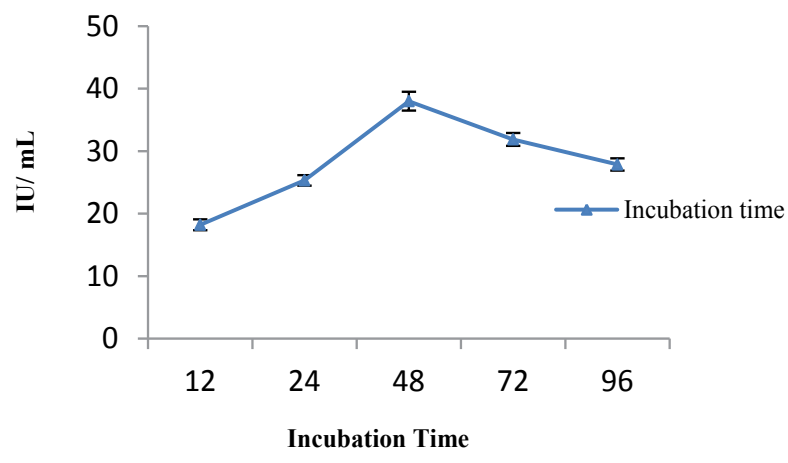

Figure 1: Effect of incubation period on Xylose reductase.

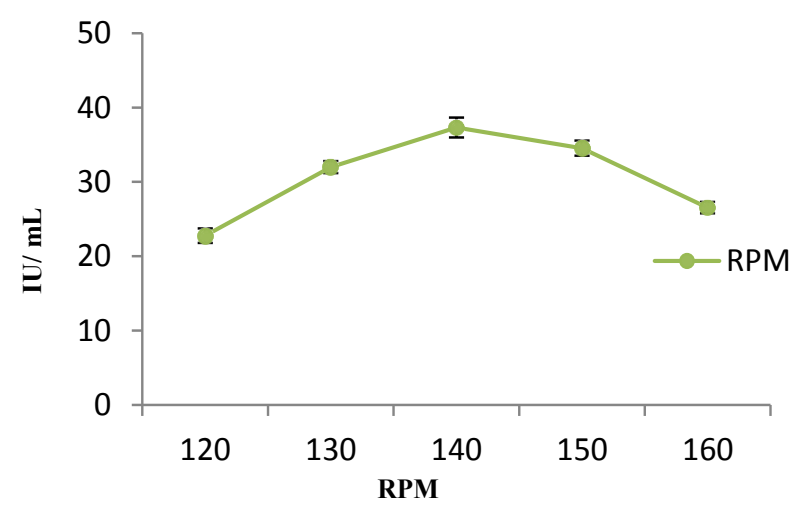

Figure 2: Effect of agitation on Xylose reductase. 


\begin{tabular}{|c|c|c|c|c|c|c|}
\hline \multirow{2}{*}{$\begin{array}{l}\text { Hemicellulose Waste } \\
\text { substrates (HWs) }\end{array}$} & \multicolumn{3}{|c|}{ Xylose reductase $(\mathrm{U} / \mathrm{mL})$} & \multicolumn{3}{|c|}{ Ethanol (mg/ml) } \\
\hline & $48 \mathrm{~h}$ & $60 \mathrm{~h}$ & $72 \mathrm{~h}$ & $48 \mathrm{~h}$ & $60 \mathrm{~h}$ & $72 \mathrm{~h}$ \\
\hline \multicolumn{7}{|l|}{$\begin{array}{l}\text { Agricultural Waste } \\
\text { substrates }\end{array}$} \\
\hline Paddy straw & $78.5 \pm 0.78$ & $83.56 \pm 1.25$ & $80.24 \pm 1.01$ & $0.80 \pm 0.07$ & $1.31 \pm 0.08$ & $0.034 \pm 0.07$ \\
\hline Sugarcane bagasse & $82.56 \pm 0.54$ & $90.42 \pm 1.97$ & $89.56 \pm 1.04$ & $1.32 \pm 0.01$ & $2.45 \pm 0.09$ & $1.42 \pm 0.10$ \\
\hline Corn cob & $112.5 \pm 0.67$ & $120.56 \pm 0.65$ & $119.58 \pm 0.15$ & $1.28 \pm 0.09$ & $2.32 \pm 0.01$ & $1.32 \pm 0.09$ \\
\hline \multicolumn{7}{|l|}{ Flour } \\
\hline Rice & $133.2 \pm 0.71$ & $145.41 \pm 0.54$ & $141.6 \pm 0.09$ & $0.99 \pm 0.07$ & $1.27 \pm 0.09$ & $1.28 \pm 0.04$ \\
\hline Wheat & $148.74 \pm 0.91$ & $158.24 \pm 1.15$ & $155.01 \pm 0.14$ & $1.20 \pm 0.08$ & $2.27 \pm 0.08$ & $2.24 \pm 0.09$ \\
\hline Finger millet & $134.56 \pm 0.99$ & $146.32 \pm 0.34$ & $143.5 \pm 0.72$ & $1.18 \pm 0.11$ & $1.22 \pm 0.09$ & $1.21 \pm 0.08$ \\
\hline \multicolumn{7}{|l|}{ Fruit Peels } \\
\hline Pomegranate Peel & $147.2 \pm 1.09$ & $171.4 \pm 1.05$ & $164.25 \pm 0.94$ & $1.24 \pm 0.09$ & $3.37 \pm 0.08$ & $2.99 \pm 0.04$ \\
\hline Sweet Lime Peel & $92.5 \pm 0.65$ & $109.34 \pm 0.75$ & $103.5 \pm 0.63$ & $0.18 \pm 0.04$ & $1.21 \pm 0.03$ & $0.20 \pm 0.04$ \\
\hline Banana Peel & $146.4 \pm 0.87$ & $169.01 \pm 1.01$ & $165.19 \pm 1.0$ & $0.24 \pm 0.09$ & $2.34 \pm 0.07$ & $0.34 \pm 0.05$ \\
\hline \multicolumn{7}{|l|}{ Oil cakes } \\
\hline Groundnut & $111.07 \pm 0.95$ & $122.7 \pm 1.5$ & $119.5 \pm 0.69$ & $0.89 \pm 0.01$ & $1.92 \pm 0.01$ & $1.12 \pm 0.001$ \\
\hline Sesame & $120.9 \pm 1.21$ & $129.4 \pm 1.35$ & $122.56 \pm 0.65$ & $0.94 \pm 0.02$ & $1.27 \pm 0.02$ & $1.07 \pm 0.002$ \\
\hline Coconut & $93.56 \pm 1.25$ & $108.54 \pm 0.73$ & $103.5 \pm 0.65$ & $1.07 \pm 0.04$ & $1.71 \pm 0.01$ & $1.12 \pm 0.02$ \\
\hline
\end{tabular}

Each value represents the mean \pm SD of triplicate experiments.

Table 3: The effect of fermentative parameters after $60 \mathrm{~h}$ fermentation of different fruit peels by Candida tropicalis strain LY15.

\begin{tabular}{|c|c|c|}
\hline HWs & Concentration of HWs & Xylitol Yield $\mathbf{~ g L}^{-\mathbf{1}}(60 \mathrm{~h})$ \\
\hline Pomegranate Peel & $2 \%$ & $\mathbf{5 5 . 5 7}$ \\
\hline Sweet Lime Peel & $2 \%$ & 14.1 \\
\hline Banana Peel & $2 \%$ & 27.2 \\
\hline
\end{tabular}

Table 4: Xylose reductase activity by wild yeast isolates.

\section{Statistical optimization of xylose reductase}

The independent variables such as inoculum (A), HWs concentrations (B), time period (C) and RPM (D) were identified as significant parameters based on the preliminary investigation (Table 1). These variables were further optimized by RSM using Box-Behnken design. Box-Behnken design, consisting of 29 experiments with 3 levels of 4 variables in coded, experimental and predicted asset value of xylose reductase activity is shown in Table 5 .

The production of enzyme was predicted by the following model:

$\mathrm{Y}(\mathrm{U} / \mathrm{mL})=170.05+2.02 \times \mathrm{A}+23.11 \times \mathrm{B}+10.45 \times \mathrm{C}+1.29 \times \mathrm{D}+5.70$ $\times$ AB-4.99 $\times$ AC-3.61 $\times$ AD- $6.98 \times \mathrm{BC}+2.11 \times \mathrm{BD}+0.073 \times \mathrm{CD}-18.25 \times$ $\mathrm{A} 2-41.88 \times \mathrm{B} 2-26.92 \times \mathrm{C} 2-14.23 \times \mathrm{D} 2$

The quadric model represents inoculum (A), HWs (B), time period (C) and RPM (D).

The statistical importance of the second-order model equation was determined by $\mathrm{F}$ test. Analysis of variance (ANOVA) for response surface quadric model is given in Table 6 . The p value is used for checking the significance of each of the coefficient. Model terms having $p$ value $<0.05$ were considered significant. The model $\mathrm{F}$ value of 120.28 implies the model is significant. There is only $0.01 \%$ chance that a large "Model $F$ value" could occur due to noise. Values of "Prob $>F$ " $<0.05$ indicate model terms are relevant. In this case A, C, A2, B2, C2 is significant model terms (Table 1 ). The multiple correlation coefficients $\left(\mathrm{R}^{2}\right)$ closer to 1 signify positive correlation between experimental and predicted values and indicate that model is precise with improved response. The reliability of the experiment is usually inversely proportional to the value of coefficient of variation $(\mathrm{CV})$. In the present study, a low $\mathrm{CV}$ (3.05\%) denotes that the experiments performed are highly reliable and

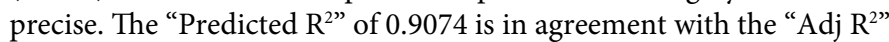
of 0.9853 . "Adeq Precision" ratio of 29.785 indicates an adequate signal due to the value greater than 4 . This model can be used to navigate the design space.

The 3D plot (Figure 3) established a visual interpretation of the regular relations between two liberated variables. Response surface were plotted to find the optimum level of each variable. The response surface plots were constructed by plotting the enzyme activity against any two independent factors. The enzyme production alters on changing the level of independent variable. The maximum enzyme production was observed with respect to the central values of these independent variables. Maximum enzyme production was obtained when the variables were at their middle to high level.

Validation of model was done by conducting experiments in triplicate using predicted optimized parameters by RSM. Highest xylose reductase activity was observed with experiment number 3 using inoculum (1\%), HWs (2\%), time period (60 h) and RPM (140). The maximum xylose reductase production by isolates was $170.05 \mathrm{U} / \mathrm{mL}$ which was found positively correlated with predicted value, i.e., $171.5 \mathrm{U} / \mathrm{mL}$.

\section{Discussion}

Hemicellulose ration of agricultural residues like eucalyptus [22], paddy straw [23,24], corn stover [25], spent grain [26], sugarcane bagasse $[27,28]$, and corncob have been employed for the effectual production of xylitol $[29,30]$. The present study revealed the first attempt towards the dual extraction of xylose reductase and bio-ethanol production from C. tropicalis strain LY 15 via pomegranate peel as a hemicellulose substrate. The agricultural residues, such as corn fiber, corn stover, rice straw, wheat straw, and sugarcane bagasses, contain of about $20-40 \%$ hemicellulose. However, most of microorganisms were inhibited by the toxic compounds expelled during the pretreatment of hemicellulose. Hence, an efficient elimination of the inhibitors is a critical step in the bioconversion process using hemicellulosic material as the HWs. In the preceding studies, various procedures had been performed for the optimization of operation bioprocess parameters. The major concerns were the treatment of HWs, time, and acid concentration to improve the yield of sugar and reduce the concentration of toxins by different kinds of detoxification. Many detoxification methods have been made 


\begin{tabular}{|c|c|c|c|c|c|c|}
\hline $\begin{array}{l}\text { Run } \\
\text { Order }\end{array}$ & $\begin{array}{c}\text { A: } \\
\text { Inoculum }\end{array}$ & B: HWs & $\begin{array}{l}\text { C: Time } \\
\text { Period }\end{array}$ & D: RPM & $\begin{array}{l}\text { Actual } \\
\text { Value }\end{array}$ & $\begin{array}{l}\text { Predicted } \\
\text { Value }\end{array}$ \\
\hline 1 & 0 & 0 & 0 & 0 & 168.01 & 170.05 \\
\hline 2 & -1 & 0 & 0 & 1 & 140.3 & 140.4 \\
\hline 3 & 0 & 0 & 0 & 0 & 171.4 & 170.05 \\
\hline 4 & 0 & -1 & 1 & 0 & 91.7 & 95.57 \\
\hline 5 & 0 & 1 & 1 & 0 & 108.3 & 127.83 \\
\hline 6 & -1 & 0 & 1 & 0 & 143.24 & 138.30 \\
\hline 7 & 1 & 1 & 0 & 0 & 145.3 & 140.75 \\
\hline 8 & -1 & -1 & 0 & 0 & 88.7 & 90.50 \\
\hline 9 & 0 & 0 & 0 & 0 & 171.45 & 170.05 \\
\hline 10 & 0 & 0 & 1 & 1 & 148.3 & 140.71 \\
\hline 11 & 0 & 0 & 1 & -1 & 147.01 & 137.98 \\
\hline 12 & 1 & 0 & -1 & 0 & 123.3 & 121.44 \\
\hline 13 & 0 & 0 & 0 & 0 & 170.15 & 170.05 \\
\hline 14 & 0 & 0 & -1 & -1 & 112.4 & 117.24 \\
\hline 15 & 1 & 0 & 0 & 1 & 134.87 & 137.27 \\
\hline 16 & 0 & -1 & -1 & 0 & 70.7 & 60.73 \\
\hline 17 & 0 & 1 & 0 & 1 & 148.4 & 140.45 \\
\hline 18 & 0 & 1 & 0 & -1 & 147.16 & 133.64 \\
\hline 19 & -1 & 0 & -1 & 0 & 112.4 & 107.43 \\
\hline 20 & 0 & 0 & 0 & 0 & 169.1 & 170.05 \\
\hline 21 & 1 & 0 & 1 & 0 & 134.2 & 132.36 \\
\hline 22 & 0 & -1 & 0 & -1 & 90.5 & 91.65 \\
\hline 23 & -1 & 0 & 0 & -1 & 123.5 & 130.65 \\
\hline 24 & -1 & 1 & 0 & 0 & 124.5 & 125.51 \\
\hline 25 & 0 & 0 & -1 & 1 & 113.4 & 119.67 \\
\hline 26 & 0 & 1 & -1 & 0 & 115.2 & 120.89 \\
\hline 27 & 0 & -1 & 0 & 1 & 83.3 & 90.02 \\
\hline 28 & 1 & -1 & 0 & 0 & 86.7 & 83.14 \\
\hline 29 & 1 & 0 & 0 & -1 & 132.5 & 141.91 \\
\hline
\end{tabular}

Table 5: Box-Behenken design along with experimental and predicted values of dependent variable.

functional to alleviate the inhibition of hydrolysate for improving microbial growth. For the xylan hydrolysate part, methods such as over liming, the use of ion-exchange resins or activated charcoal adsorption was found to eradicate most of the toxins [31].

Oxygen is a critical parameter in the accumulation of xylitol. Microorganisms require sufficient oxygen to increase biomass. The effects of agitation on both biomass and xylitol production were investigated at different rpm (120 to 160). Lower shaking speed favored the xylitol accumulation, while higher shaking speed augmented the biomass production. In brief, more oxygen supply resulted in the maximum yield of biomass and lower yield of xylitol $[32,33]$.

Pomegranate peel attributes high xylitol production with an increased biomass yield. The presence of other HWs attributes towards lower activities of enzymes and biomass yield. The above analysis reveals that the addition of pomegranate peel improves the xylitol efficiency using C. tropicalis strain LY 15. Fermentation was carried out in 250 $\mathrm{mL}$ erlenmeyer flasks containing $50 \mathrm{~mL}$ of the production medium with pomegranate peel. The inoculum size was kept $1 \%$ and flasks were kept for different time periods. At $60 \mathrm{~h}$, xylitol concentration achieved the maximum yield by producing maximum enzyme.

The high solids culture model was applied for inhibitors degradation by C. tropicalis strain LY 15 on the pretreated pomegranate peel directly in the liquid hydrolysate. No cellulose degradation were observed in the $C$. tropicalis strain LY 15 culture on hydrolysates containing highly cellulose-rich solids, and thus the cellulose loss could be avoided in the aerobic stage. In this context, this step-line process is considerable; there were no additional operation units, no sugar loss and combine inhibitor degradation, xylitol fermentation, and ethanol production.

Conversion of xylose to xylitol is by reduction and oxidation process [34]. The NADH or NADPH dependent xylose reductase (XR) plays a pivot role in the reduction of xylose into xylitol during the first step. Then, NAD+relying on xylitol dehydrogenase (XDH) oxidized xylitol to xylulose. $\mathrm{XR}, \mathrm{XDH}$ and the cofactors (NADPH and NAD+) (NADPH and NAD+) [31] were the key modulators affecting the xylitol accumulation. In Candida sp., XR and XDH are more NADPH dependent and NAD+ dependent respectively $[35,36]$. $\mathrm{NADP}+$ is reduced to NADPH in the preliminary step of the pentose phosphate pathway. NADH generated in the second step is oxidized in the respiratory chain [37]. There are several reports on the production of bioethanol by utilizing yeast $[38,39]$. Sasikumar and Viruthagiri [40] stated Kluyveromyces fragilis-NCIM 0557 preferable capacity to convert hexose to ethanol by central composite design. Response surface methodology (RSM) is another statistical process to improve enzyme yield by using designing minimum number of experiments for giant number of motives [41]. The enzymatic production of glucose is dependent upon the concentration of pomegranate peel which resulted in an increased concentration of ethanol for a longer $(60 \mathrm{~h})$ fermentation period.

In this study, the isolate degrades pomegranate peel to xylitol by secreting xylose reductase under aerobic conditions and ethanol under anaerobic conditions. A comparative study was reviewed to understand the yield of xylitol from yeast isolates using various substrates (Table 7). The higher yield of xylitol and ethanol production by C. tropicalis strain LY15 was carried out by metabolic shift from aerobic conditions to anaerobic. This process lowered the possibility of contamination by other microbial organisms since only a single inoculation was needed. This process makes more preferable this process was more

\begin{tabular}{|c|c|c|c|c|c|c|}
\hline Source & $\begin{array}{l}\text { Sum of } \\
\text { Squares }\end{array}$ & df & $\begin{array}{l}\text { Mean } \\
\text { Square }\end{array}$ & F Value & $\begin{array}{l}\text { p-value } \\
\text { Prob }>F\end{array}$ & \\
\hline Model & 22488.40 & 14 & 1606.31 & 17.70 & $<0.0001$ & Significant \\
\hline A-Inoculum & 48.92 & 1 & 48.92 & 0.54 & 0.4749 & \\
\hline B-HWs & 6406.09 & 1 & 6406.09 & 70.60 & $<0.0001$ & \\
\hline $\begin{array}{l}\text { C-Time } \\
\text { Period }\end{array}$ & 1309.39 & 1 & 1309.39 & 14.43 & 0.0020 & \\
\hline D-RPM & 20.02 & 1 & 20.02 & 0.22 & 0.6458 & \\
\hline $\mathrm{AB}$ & 129.96 & 1 & 129.96 & 1.43 & 0.2513 & \\
\hline$A C$ & 99.40 & 1 & 99.40 & 1.10 & 0.3130 & \\
\hline$A D$ & 52.06 & 1 & 52.06 & 0.57 & 0.4614 & \\
\hline$B C$ & 194.60 & 1 & 194.60 & 2.14 & 0.1652 & \\
\hline$B D$ & 17.81 & 1 & 17.81 & 0.20 & 0.6645 & \\
\hline$C D$ & 0.021 & 1 & 0.021 & $2.317 \mathrm{E}-004$ & 0.9881 & \\
\hline $\mathrm{A} 2$ & 2160.39 & 1 & 2160.39 & 23.81 & 0.0002 & \\
\hline B2 & 11377.51 & 1 & 11377.51 & 125.38 & $<0.0001$ & \\
\hline $\mathrm{C} 2$ & 4700.64 & 1 & 4700.64 & 51.80 & $<0.0001$ & \\
\hline D2 & 1314.14 & 1 & 1314.14 & 14.48 & 0.0019 & \\
\hline Residual & 1270.38 & 14 & 90.74 & & & \\
\hline Lack of Fit & 1261.06 & 10 & 126.11 & 54.16 & 0.0008 & Significant \\
\hline Pure Error & 9.31 & 4 & 2.33 & & & \\
\hline $\begin{array}{c}\text { Cor Total } \\
23758.78 \\
28\end{array}$ & 23758.78 & 28 & & & & \\
\hline
\end{tabular}

$\mathrm{R}^{2}$ : 0.9465; Adj R²: 0.8931; Predicted R²: 0.6937; CV: 7.43\%; Adeq precision 15.958; $\mathrm{df}=$ degree of freedom; Highly significant, $p \leq 0.0001$; Significant, $p \leq 0.05$; Non- significant, $p>0.05$

Table 6: Analysis of variance (ANOVA) for Xylose reductase activity as a function of independent variables. 


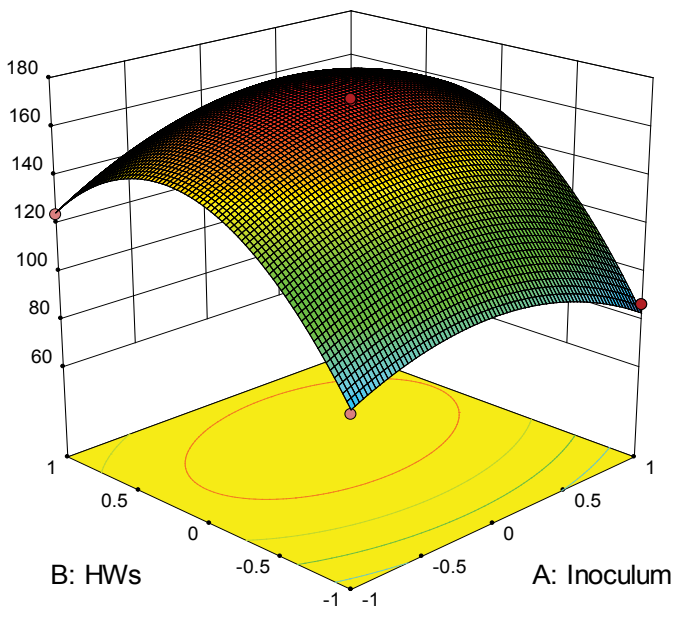

a)

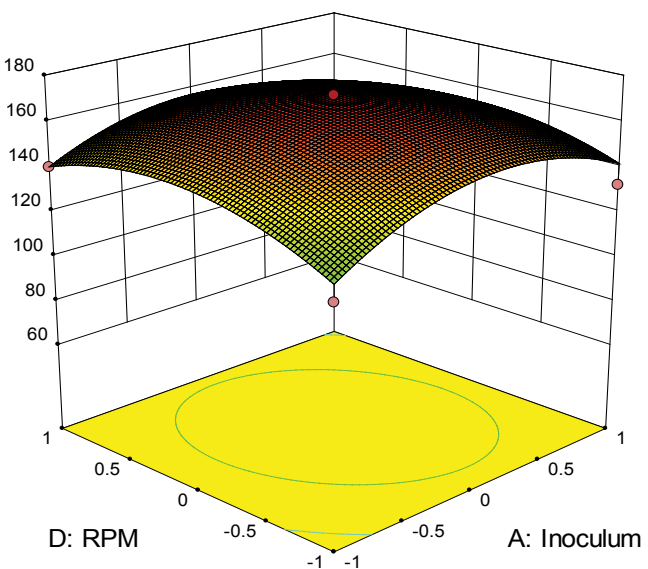

c)

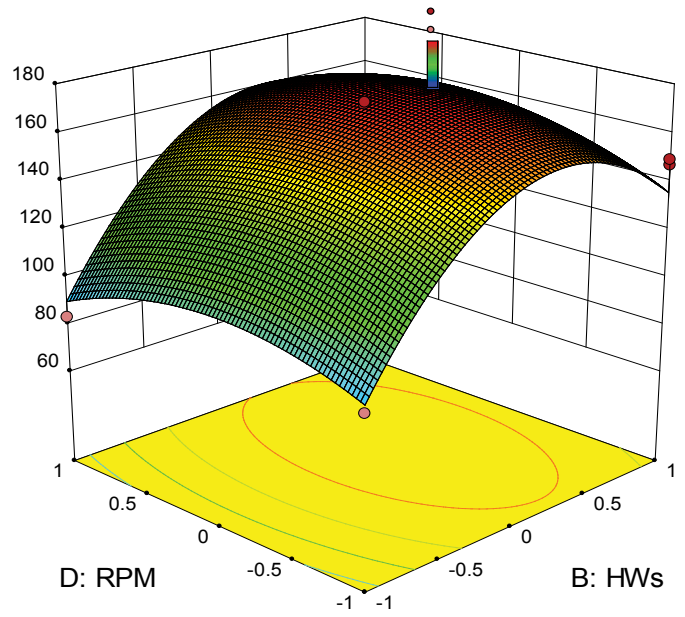

e)

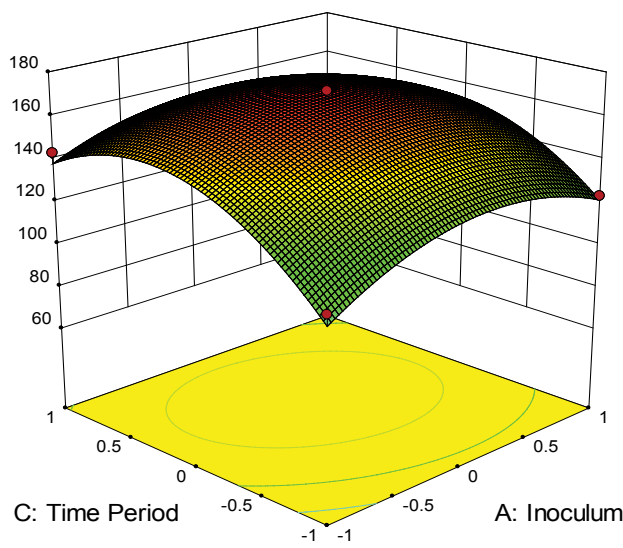

b)

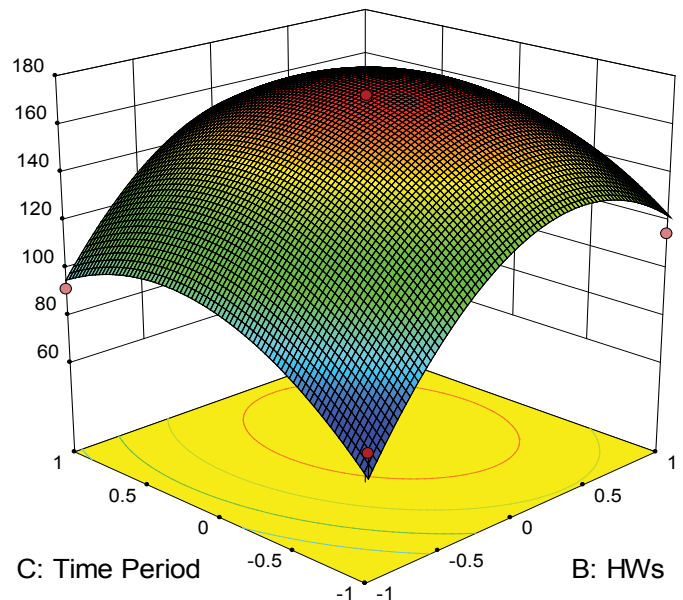

d)

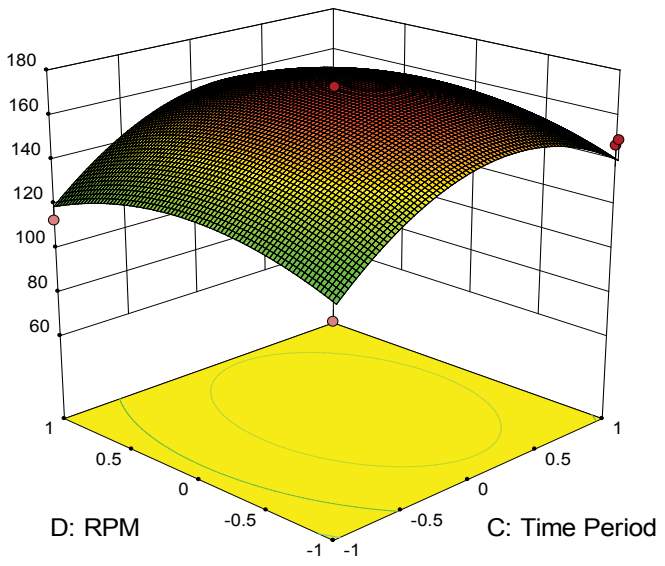

f)

Figure 3: Response surface plot showing interaction between four variables for enzyme activity. (a) HWs and Inoculum (b) Time period and Inoculum (c) RPM and Inoculum (d) Time period and HWs (e) RPM and HWs (f) RPM and Time period. 
Citation: Barathikannan K, Khusro A, Paul A (2016) Simultaneous Production of Xylitol and Ethanol from Different Hemicellulose Waste Substrates by Candida tropicalis Strain Ly15. J Bioprocess Biotech 6: 289. doi:10.4172/2155-9821.1000289

Page 7 of 8

\begin{tabular}{|c|c|c|c|c|c|c|c|}
\hline Strains & Wild/Mutant & Method & Carbon source & XR (IU/mL) & Xylitol & Ethanol & References \\
\hline C. tropicalis LY15 & Wild & BBD, RSM & Pomegranate peel & 171.4 & $55.57\left(\mathrm{~g} \mathrm{l}^{-1}\right) 60 \mathrm{~h}$ & $3.37 \mathrm{~g} \mathrm{l}^{-1}$ & Present study \\
\hline $\begin{array}{l}\text { Candida tropicalis } \\
\text { W103 }\end{array}$ & Wild & Non-statistical & Corncob & - & $17.1 \mathrm{~g} \mathrm{l}^{-1}$ & $25.3 \mathrm{~g} \mathrm{l}^{-1}$ & Cheng et al. \\
\hline C. tropicalis & Wild & Non-statistical & $\begin{array}{c}\text { Meranti wood sawdust } \\
\text { (MWS) }\end{array}$ & 11.16 & - & - & Rafiqul and Sakinah \\
\hline
\end{tabular}

Table 7: Evaluation of simultaneous production of $\mathrm{XR}$, xylitol and Ethanol by Candida sp.

preferable, no sugar loss, inhibitor detoxification, higher the degree of xylitol fermentation and higher the capacity of ethanol production in the same bio reactor. A simple approach to remove ethanol from the fermentation broth carried out by evaporation and further purification of concentrated xylitol by crystallization due to variation in the boiling points of ethanol and xylitol production using xylitol reductase.

\section{Conclusion}

The potential isolates Candida tropicalis strain LY15 completely consumes pomegranate peel and obtained valuable yield of xylose reductase. It effectively integrates hemicellulosic hydrolysate and converts to xylitol for bioconversion. This study evidences that strain Candida tropicalis strain LY15 could be possibly subjugated for the industrial xylose reductase production from pomegranate peel under statistically optimal conditions. Xylose reductase yields nearer to the maximum predicted value have been reached from pomegranate peel hemicellulose by our isolate. The co-production of ethanol makes the process more gainful and also vanishing of ethanol over xylitol makes the reclamation process cost-effective. Further investigation is in progress to produce xylitol using pomegranate peel as substrate and to clone xylitol producing gene of C. tropicalis strain LY15 into Saccharomyces sp.

\section{Conflict of Interest}

The authors declare that they have no conflict of interest.

\section{Acknowledgements}

The authors would like to thank Department of Biotechnology, India (IndoSpain Collaborative project) for partial financial assistance. We are acknowledging with thanks for Prof. Sathyanarayana N Gummadi, Indian Institute of Technology Madras for HPLC analysis.

\section{References}

1. Gomez LD, Steele King CG, McQueen, Mason SJ (2008) Sustainable liquid biofuels from biomass: the writing's on the walls. New Phytol 178: 473-485.

2. Kim JH, Block DE, Mills DA (2010) Simultaneous consumption of pentose and hexose sugars: an optimal microbial phenotype for efficient fermentation of lignocellulosic biomass. Appl Microbiol Biotechno 88: 1077-1085.

3. Barathikannan K, Agastian P (2016) Xylitol: Production, Optimization and Industrial Application. Int J Curr Microbiol App Sci 5: 324-339.

4. Saha BC (2003) Hemicellulose bioconversion. J Ind Microbiol Biotechnol 30: 279-291.

5. Pappu JSM, Gummadi SN (2016) Multi response optimization for enhanced xylitol production by Debaryomyces nepalensis in bioreactor. 3 Biotech 6: 1-10.

6. Barathikannan K, Khusro A, Agastian P (2016) Isolation and molecular characterization of xylitol producing wild yeast strains from different fermented fruit juices. South Indian J Biol Sci 2: 415-423.

7. Franceschin G, Zamboni A, Bezzo F, Bertucco A (2008) Ethanol from corn: a technical and economical assessment based on different scenarios. Chem Eng Res Des 86: 488-498.

8. Bae SM, Park YC, Lee TH, Kweon DH, Choi JH, et al. (2004) Production of xylitol by recombinant Saccharomyces cerevisiae containing xylose reductase gene in repeated fed-batch and cell-recycle fermentations. Enzyme Microb Technol 35: 545-549.

9. Nyyssölä A, Pihlajaniemi A, Palva A, Von Weymarn N, Leisola M (2005) Production of xylitol from $d$-xylose by recombinant Lactococcus lactis. J Biotechnol 118: 55-66.
10. Ko BS, Kim J, Kim JH (2006) Production of xylitol from D-xylose by a xylitol dehydrogenase gene-disrupted mutant of Candida tropicalis. Appl Environ Microbiol 72: 4207-4213.

11. Prakasham R, Rao RS, Hobbs PJ (2009) Current trends in biotechnological production of xylitol and future prospects. Curr Trends Biotechnol Pharm 3: 8-36.

12. Rodrigues R, Felipe M, Silva J, Vitolo M, Gómez P (2001) The influence of $\mathrm{pH}$, temperature and hydrolyzate concentration on the removal of volatile and nonvolatile compounds from sugarcane bagasse hemicellulosic hydrolyzate treated with activated charcoal before or after vacuum evaporation. Braz $J$ Chem Eng18: 299-311.

13. Rao RS, Jyothi CP, Prakasham R, Sarma P, Rao LV (2006) Xylitol production from corn fiber and sugarcane bagasse hydrolysates by Candida tropicalis. Bioresour Technol 97: 1974-1978.

14. Canilha L, Carvalho W, Giulietti M, Felipe MDGA, Silva AE, et al. (2008) Clarification of a wheat straw-derived medium with ion-exchange resins for xylitol crystallization. J Chem Technol Biotechnol 83: 715-721.

15. West TP (2009) Xylitol production by Candida species grown on a grass hydrolysate.World J Microbiol Biotechnol 25: 913-916.

16. Yahashi Y, Horitsu H, Kawai K, Suzuki T, Takamizawa K (1996) Production of xylitol from $D$-xylose by Candida tropicalis: the effect of $D$-glucose feeding. $J$ Ferment Bioeng 81: 148-152.

17. Claassen P, Van Lier J, Contreras AL, Van Niel E, Sijtsma L, et al. (1999) Utilisation of biomass for the supply of energy carriers. Appl Microbio Biotechnol 52: 741-755.

18. Prasad S, Singh A, Joshi H (2007) Ethanol as an alternative fuel from agricultural, industrial and urban residues. Resour Conserv Recy 50: 1-39.

19. Rabelo S, Carrere H, Maciel Filho R, Costa A (2011) Production of bioethanol methane and heat from sugarcane bagasse in a biorefinery concept. Bioresour Technol 102: 7887-7895.

20. loelovich M (2015) Recent findings and the energetic potential of plant biomass as a renewable source of biofuels-a review. BioResources 10: 1879-1914.

21. Adeeyo OA, Oresegun OM, Oladimeji TE (2015) Compositional analysis of lignocellulosic materials: Evaluation of an economically viable method suitable for woody and non-woody biomass. American Journal of Engineering Research (AJER) 4: 14-19

22. Felipe M, Alves L, Silva S, Roberto I, Mancilha I, et al. (1996) Fermentation of eucalyptus hemicellulosic hydrolysate to xylitol by Candida guilliermondii. Bioresource Technology 56: 281-283.

23. Liaw WC, Chen CS, Chang WS, Chen KP (2008) Xylitol production from rice straw hemicellulose hydrolyzate by polyacrylic hydrogel thin films with immobilized Candida subtropicalis WF79. J Biosci Bioeng 105: 97-105.

24. Swain MR, Krishnan C (2015) Improved conversion of rice straw to ethanol and xylitol by combination of moderate temperature ammonia pretreatment and sequential fermentation using Candida tropicalis. Ind Crops Prod 77 1039-1046.

25. de Mancilha IM, Karim MN (2003) Evaluation of ion exchange resins for removal of inhibitory compounds from corn stover hydrolyzate for xylitol fermentation. Biotechnol Prog 19: 1837-1841.

26. Mussatto SI, Dragone G, Roberto IC (2005) Influence of the toxic compounds present in brewer's spent grain hemicellulosic hydrolysate on xylose-to-xylitol bioconversion by Candida guilliermondii. Process Biochem 40: 3801-3806.

27. Carvalho W, Santos J, Canilha L, Silva S, Perego P, et al. (2005) Xylito production from sugarcane bagasse hydrolysate: Metabolic behaviour of Candida guilliermondii cells entrapped in Ca-alginate. Biochem Eng J 25: 25-31.

28. Vallejos ME, Chade M, Mereles EB, Bengoechea DI, Brizuela JG, et al. (2016) Strategies of detoxification and fermentation for biotechnological production of xylitol from sugarcane bagass. Ind Crops Prod 91:161-169. 
Citation: Barathikannan K, Khusro A, Paul A (2016) Simultaneous Production of Xylitol and Ethanol from Different Hemicellulose Waste Substrates by Candida tropicalis Strain Ly15. J Bioprocess Biotech 6: 289. doi:10.4172/2155-9821.1000289

Page 8 of 8

29. Latif F, Rajoka MI (2001) Production of ethanol and xylitol from corn cobs by yeasts. Bioresour Technol 77: 57-63.

30. Ding X, Xia L (2006) Effect of aeration rate on production of xylitol from corncob hemicellulose hydrolysate. Appl Biochem Biotechnol 133: 263-270.

31. Ikeuchi T, Azuma M, Kato J, Ooshima H (1999) Screening of microorganisms for xylitol production and fermentation behavior in high concentrations of xylose. Biomass Bioenergy 16: 333-339.

32. Sampaio FC, Torre P, Passos FML, Perego P, Passos FJV, et al. (2004) Xylose Metabolism in Debaryomyces hansenii UFV-170. Effect of the Specific Oxygen Uptake Rate. Biotechnol Prog 20: 1641-1650.

33. Ping Y, Ling HZ, Song G, Ge JP (2013) Xylitol production from non-detoxified corncob hemicellulose acid hydrolysate by Candida tropicalis. Biochem Eng $\mathrm{J}$ 75: 86-91.

34. Chiang C, Knight S (1960) Metabolism of D-xylose by moulds. Nature 188: 79-81.

35. Yablochkova E, Bolotnikova O, Mikhailova N, Nemova N, Ginak A (2004) The activity of key enzymes in xylose-assimilating yeasts at different rates of oxygen transfer to the fermentation medium. Microbiol 73: 129-133.
36. Yokoyama SI, Suzuki T, Kawai K, Horitsu H, Takamizawa K (1995) Purification characterization and structure analysis of NADPH-dependent D-xylose reductases from Candida tropicalis. J Ferment Bioengineer 79: 217-223.

37. Winkelhausen E, Kuzmanova S (1998) Microbial conversion of D-xylose to xylitol. J Ferment Bioengineer 86: 1-14.

38. Lark N, Xia Y, Qin CG, Gong C, Tsao G (1997) Production of ethanol from recycled paper sludge using cellulase and yeast, Kluveromyces marxianus. Biomass Bioenergy 12: 135-143.

39. Zhang YHP, Lynd LR (2005) Cellulose utilization by Clostridium thermocellum: bioenergetics and hydrolysis product assimilation. Proc Natl Acad Sci USA 102 7321-7325.

40. Sasikumar E, Viruthagiri T (2008) Optimization of process conditions using response surface methodology (RSM) for ethanol production from pretreated sugarcane bagasse: kinetics and modeling. Bioenergy Res 1: 239-247.

41. Khusro A, Barathi Kannan K, Al-Dhabi NA, Arasu MV, Agastian P (2016) Statistical optimization of thermo-alkali stable xylanase production from Bacillus tequilensis strain ARMATI. Electron J Biotechnol 22: 16-25. 